Vol. 12 No 1 Juni 2017, hal. 58-62

\title{
PENGARUH MOTIVASI INTRINSIK DAN EKSTRINSIK TERHADAP PRESTASI MATA PELAJARAN EKONOMI
}

\author{
Qurratul Aini'1) Mawardi'2) Baiq Yuliana Rizkiawati3) \\ 1. pendidikan Ekonomi, Universitas Hamzanwadi \\ Email: aquirratul77@gmail.com \\ 2. pendidikan Bahasa Inggris, Universitas Gunung Rinjani \\ Email: amin.mawardi@yahoo.com \\ 3. Pendidikan Ekonomi, Universitas Hamzanwadi \\ Email: baiq_rizki@yahoo.co.id
}

\begin{abstract}
This study aims to study intrinsic and extrinsic learning motivation towards economic learning achievement of NW high school students. This research is a correlative descriptive research with a sample of 106 students selected using the Simple Random Sampling Technique. Data collection uses questionnaires and Documentation techniques. The collected data was then analyzed by descriptive and inferential statistical techniques. The results showed: 1) the partial intrinsic learning motivation was significantly significant towards economic learning achievement with $F$ count $=14.083$, significance $(p)<0.05$ and contribution of $14.89 \%$; 2) partial extrinsic learning motivation does not challenge significantly on economic learning achievement at NW Pancor High School with a calculated $F$ value $=3.192$ and significance ( $p$ ) of $0.078 p>0.05$ and benefits of 3.8\%; 3) intrinsic learning motivation and extrinsic learning motivation together with importance to student learning achievement, with $F$ count $=7.703$, significance value $(p)<0.05$, and contribution of $16.1 \%$.
\end{abstract}

Key Words: Intrinsic, Learning, Motivation, Extrinsic, Economic, Achievement.

\begin{abstract}
Abstrak
Penelitian ini bertujuan untuk mengetahui pengaruh motivasi belajar intrinsik dan ekstrinsik terhadap prestasi belajar ekonomi siswa SMA NW. Penelitian ini merupakan Penelitian Deskriptif Korelatif dengan sampel 106 siswa yang dipilih dengan Simple Random Sampling Technique. Pengumpulan data menggunakan angket dan teknik Dokumentasi. Data yang terkumpul kemudian dianalisis dengan teknik statistik deskriptif dan inferensial. Hasil Penelitian menunjukkan bahwa: 1) motivasi belajar intrinsik secara parsial berpengaruh secara signifikan terhadap prestasi belajar ekonomi dengan $F$ hitung $=14,083$, signifikansi $(p)<0,05$ dan kontribusi sebesar 14,89\%; 2) motivasi belajar ekstrinsik secara parsial tidak berpengaruh secara signifikan terhadap prestasi belajar ekonomi di SMA NW Pancor dengan nilai $F$ hitung = 3,192 dan signifikansi (p) sebesar 0,078 p>0,05 dan kontribusi sebesar 3,8\%; 3) motivasi belajar intrinsik dan motivasi belajar ekstrinsik secara bersama-sama berpengaruh secara signifikan terhadap prestasi belajar siswa, dengan $F$ hitung $=7,703$, nilai signifikansi $(p)<0,05$, dan kontribusi sebesar $16,1 \%$.
\end{abstract}

Kata Kunci : intrinsik, Belajar, Motivasi, Ekstrinsik, Ekonomi, Prestasi. 


\section{PENDAHULUAN}

Pendidikan, tidak diragukan lagi, merupakan satu aspek pembangunan yang mendapat prioritas utama di antara yang lain. Tujuan pendidikan adalah memberikan pengalaman belajar yang meliputi domain kognitif, afektif, dan psikomotorik secara bermakna, yang berfungsi menyiapkan siswa menjalani kehidupan dalam era global yang sangat kompleks ini.

Prestasi belajar merupakan output dari pendidikan formal maupun non formal. Osokoya (1998) juga mengatakan bahwa prestasi merupakan akhir dari pengalaman belajar. Mendapat prestasi tinggi merupakan output yang diinginkan oleh guru, orang tua dari anak-anak dan siswa-siswi mereka. Demikian pula, baik guru maupun sekolahsekolah pada umumnya digrade secara kualitatif berdasarkan prestasi yang diraih oleh siswa-siswi mereka.

Prestasi belajar secara umum didefinisikan sebagai perwujudan pengetahuan yang diperoleh serta skill yang dikembangkan di mata pelajaran (Busairi, 2000). Prestasi merupakan "level of performance in school subject as exhibited by individual" (Iroegbu, 1992). Nilai-nilai yang dikeluarkan oleh guru merupakan indikator-indikator dari prestasi ini. Nilai-nilai yang dikeluarkan oleh sekolah ini bisa tinggi, sedang, dan rendah yang artinya bahwa prestasi belajar bisa baik atau buruk. Siswa dikatakan berhasil jika dapat mencapai batas Kriteria Ketuntasan Minimal (KKM) yang ditentukan oleh sekolah yang bersangkutan. Namun, permasalahan yang selalu menjadi kendala dalam bidang pendidikan umumnya dan dalam konteks penelitian ini SMA Nahdlatul Wathan Pancor Lombok Timur Nusa Tenggara Barat (NTB) adalah rendahnya prestasi belajar sebagian siswa yang diketahui dari hasil ulangan harian, mid maupun semester yang belum mencapai kriteria KKM yang sudah ditentukan. Berdasarkan preliminary observation, KKM pada mata pelajaran Ekonomi di SMA Nahdlatul Wathan Pancor sebesar 72 untuk Kelas XI dan 75 untuk Kelas XII. Ini menunjukkan bahwa prestasi belajar yang menjadi tolok ukur keberhasilan belajar belum sepenuhnya sesuai yang diharapkan.

Banyak faktor telah dikutip terkait dengan rendahnya prestasi belajar siswa dalam bidang ekonomi. Secara teoritis, ada beberapa faktor yang mempengaruhi prestasi belajar antara lain: faktor internal dan faktor eksternal (Dalyono, 2005). Faktor internal berasal dari dalam diri sendiri, sedangkan faktor eksternal berasal dari luar diri siswa. Faktor yang berasal dari luar meliputi faktor-faktor yang berhubungan dengan lingkungan sekolah, lingkungan masyarakat serta lingkungan keluarga. Sedangkan faktor yang timbul dari dalam diri siswa berupa kondisi kesehatan (health condition), intelegensi dan bakat (intelligence and talent), minat (interest), motivasi (motivation), dan cara belajar (learning style).

Teori Dalyono ini menegaskan bahwa motivasi merupakan salah satu faktor internal yang memiliki peran penting dalam keberhasilan pembelajaran karena motivasi belajar merupakan kekuatan mental yang mendorong terjadinya proses belajar. Siswa memerlukan motivasi agar mereka bersemangat; tanpa ada motivasi, maka tujuan pembelajaran yang telah ditetapkan tidak akan tercapai. Secara ringkas, motivasi belajar adalah dorongan internal dan eksternal pada siswa-siswi yang sedang belajar untuk mengadakan perubahan tingkah laku, pada umumnya dengan beberapa indikator atau unsur yang mendukung. Definisi ini menegaskan bahwa motivasi belajar terdiri dari dua jenis, yaitu intrinsik dan ekstrinsik. Hal ini sesuai dengan apa yang Uno

DOI: 10.29408/edc.v12i1.1320 
(2011: 24) jelaskan bahwa motivasi belajar adalah daya pendorong baik dorongan internal (motivasi intrinsik) maupun eksternal (motivasi ekstrinsik) yang berfungsi untuk menggerakkan dan mengarahkan kegiatan belajar demi tercapainya tujuan belajar.

Pada dasarnya motivasi yang diharapkan oleh siswa adalah motivasi intrinsik, akan tetapi motivasi ini tidak selalu dapat muncul. Oleh karena itu motivasi ekstrinsik juga merupakan unsur penting bagi para siswa, karena pemberian motivasi menjadi faktor yang memberi pengaruh bagi pencapaian hasil belajar atau kesuksesan seseorang. Motivasi ekstrinsik timbul karena adanya rangsangan (stimulus) dari luar baik berbentuk: penghargaan, lingkungan belajar yang kondusif, dan kegiatan belajar yang menarik. Semakin tinggi tingkat motivasi belajar siswa, baik motivasi intrinsik maupun ekstrinsik, maka akan semakin baik perolehan hasil belajarnya. Sebaliknya, apabila motivasi belajar siswa rendah, maka siswa akan mendapatkan kesulitan untuk mencapai hasil belajar yang baik.

Tujuan yang ingin dicapai dalam penelitian ini yaitu untuk mengetahui seberapa besar pengaruh motivasi intrinsik terhadap prestasi dan seberapa besar pengaruh motivasi ekstrinsik terhadap prestasi serta pengaruhnya secara bersama-sama terhadap belajar ekonomi siswa SMA Nahdlatul Wathan Pancor Lombok Timur Nusa Tenggara Barat.

\section{METODE PENELITIAN}

Berdasarkan rumusan masalah pada penelitian ini, maka pendekatan yang paling tepat digunakan adalah pendekatan kuantitatif. Penelitian ini termasuk jenis penelitian korelasi (correlational research), yakni penelitian yang meneliti tentang ada tidaknya dan seberapa besar hubungan antar variabel-variabel yang diteliti. Penelitian ini juga bisa disebut penelitian ex-post facto, karena dalam penelitian ini tidak dibuat perlakuan/manipulasi terhadap variabel-variabelnya, tetapi hanya mengungkap fakta berdasarkan gejala yang telah ada pada diri responden. Populasi dalam penelitian ini adalah seluruh siswa SMA Nahdlatul Wathan Kelas XI IPS dan Kelas XII IPS Tahun Ajaran 2014 yang berjumlah 149 orang siswa yaitu: 40 orang siswa Kelas XI IPS 1, 39 orang Kelas XI IPS 2, 38 siswa Kelas XII IPS 1, dan 32 siswa di Kelas XII IPS 2. Teknik sampling (sampling technique) yang dipilih adalah Simple Random Sampling karena jumlah sampel yang diambil ditentukan dengan cara acak tanpa memperhatikan tingkatan yang ada dalam populasi; tiap elemen populasi memiliki peluang yang sama. Dengan menggunakan rumus Slovin, didapatkan jumlah sampel sebesar 106 siswa. Dalam penelitian ini data yang meliputi data primer dan data sekunder dikumpulkan dengan menggunakan teknik Angket (questionaire) dan Dokumentasi (documentation).

Teknik analisis yang digunakan adalah analisis statistik deskriptif dan teknik analisis inferensial yang meliputi uji $F$ dan uji t. Uji $F$ digunakan untuk menguji signifikansi variabel motivasi belajar intrinsik dan esktrinsik terhadap prestasi belajar ekonomi. Sedangkan uji t digunakan untuk menguji signifikansi pengaruh motivasi belajar intrinsik terhadap prestasi belajar ekonomi dan pengaruh motivasi belajar ekstrinsik terhadap prestasi belajar ekonomi. 


\section{HASIL PENELITIAN DAN PEMBAHASAN}

Penelitian ini mendeskripsikan dan menguji pengaruh variabel terikat terhadap variabel bebas, maka pada bagian ini disajikan deskripsi data dari masing-masing variabel berdasarkan data yang telah diperoleh.

Tabel 1 Hasil Analisis Deskriptif Variabel Motivasi Belajar Intrinsik ( $\left.\mathrm{X}_{1}\right)$, Ekstrinsik ( $\left.\mathrm{X}_{2}\right)$ dan Prestasi Belajar (Y)

\begin{tabular}{|l|r|r|r|}
\hline & $\begin{array}{c}\text { Motivasi } \\
\text { Intrinsik }\end{array}$ & $\begin{array}{c}\text { Motivasi } \\
\text { Ekstrinsik }\end{array}$ & $\begin{array}{c}\text { Prestasi } \\
\text { Belajar }\end{array}$ \\
\hline N Valid & 83 & 83 & 83 \\
Mean & 1 & 1 & 1 \\
Std. Error of Mean & 81.4096 & 48.1205 & 79.4337 \\
Median & .81692 & .35315 & .80161 \\
Mode & 81.0000 & 48.0000 & 80.0000 \\
Std. Deviation & 79.00 & 49.00 & 76.50 \\
Variance & 7.44252 & 3.21732 & 7.30301 \\
Range & 55.391 & 10.351 & 53.334 \\
Minimum & 32.00 & 15.00 & 37.50 \\
Maximum & 66.00 & 41.00 & 58.00 \\
Sum & 98.00 & 56.00 & 95.50 \\
\hline
\end{tabular}

Sumber: Data diolah (2014)

Berdasarkan Tabel 1 didapatkan kategori tingkat motivasi belajar intrinsik dan ekstrinsik siswa sebagai berikut:

1. Tingkat motivasi belajar intrinsik siswa 14,5\% (12 siswa) berada dalam kategori kurang (<74), 68,7\% (57 siswa) dalam kategori sedang (74-89), dan 16,9\% (14 siswa) dalam kategori motivasi tinggi $(>89)$.

2. Tingkat motivasi belajar ekstrinsik siswa 15\% (13 siswa) berada dalam kategori kurang (<45), 67\% (55 siswa) dalam kategori sedang (45-51), dan 18\% (15 siswa) dalam kategori motivasi tinggi $(>51)$.

3. Tingkat prestasi belajar siswa $8,4 \%$ (7 siswa) berada dalam kategori kurang $(<72)$, 82\% (22 siswa) dalam kategori sedang (72-87), dan 9,6\% (8 siswa) dalam kategori motivasi tinggi $(>87)$.

Berdasarkan kategori tersebut didapat kesimpulan bahwa motivasi belajar intrinsik, motivasi belajar ekstrinsik, dan prestasi belajar siswa SMA Nahdlatul Wathan Pancor berada dalam kategori sedang.

Selanjutnya pengujian hipotesis dilakukan untuk mengetahui pengaruh variabel bebas terhadap variabel terikat. Ada tiga hipotesis yang diuji dalam penelitian ini yaitu 1) ada pengaruh yang signifikan motivasi belajar intrinsik terhadap prestasi belajar DOI: 10.29408/edc.v12i1.1320 
ekonomi, 2) ada pengaruh yang signifikan motivasi belajar ekstrinsik terhadap prestasi belajar ekonomi, 3) ada pengaruh yang signifikan motivasi belajar intrinsik dan motivasi belajar ekstrinsik secara bersama-sama terhadap prestasi belajar ekonomi. Hipotesis 1 dan 2 diuji dengan menggunakan analisis regresi linier sederhana, sedangkan untuk hipotesis 3 diuji dengan menggunakan analisis regresi linier ganda. Semua pengujian dilakukan dengan bantuan program SPSS 16.0 for Windows pada taraf signifikansi 0,05 (5\%) dengan hasil seperti bisa dilihat pada Tabel 2.

Tabel 2 Ringkasan Hasil Analisis untuk Pengujian Hipotesis Penelitian

\begin{tabular}{|c|c|c|c|}
\hline & Persamaan Garis Regresi & $\begin{array}{c}\text { Koefisien } \\
\text { Korelasi }\end{array}$ & $\begin{array}{c}\text { Kontribusi } \\
(\%)\end{array}$ \\
\hline$X_{1}$ dengan $\mathrm{Y}$ & $\mathrm{Y}=48,690+0,378 X_{1}$ & 0,385 & $14,8 \%$ \\
\hline$X_{2}$ dengan $\mathrm{Y}$ & $\mathrm{Y}=58,165+0,442 \mathrm{X}_{2}$ & 0,195 & $3.8 \%$ \\
\hline $\begin{array}{c}X_{1} \text { dan } X_{2}, \\
\text { dengan } \mathrm{Y}\end{array}$ & $\mathrm{Y}=37,772+0,353 \mathrm{X}_{1}+0,269 \mathrm{X}_{2}$ & 0,402 & $16,1 \%$ \\
\hline
\end{tabular}

Sumber: data diolah (2014)

Keterangan:

$X_{1}=$ Motivasi Intrinsik

$X_{2}=$ Motivasi Ekstrinsik

$\mathrm{Y}=$ Prestasi Belajar Ekonomi

Dari Tabel 2 dapat disimpulkan: (1) ada pengaruh yang signifikan motivasi intrinsik $\left(X_{1}\right)$ terhadap prestasi belajar Ekonomi $(Y)$, dengan persamaan garis regresi $Y=48,690$ $+0,378 X_{1}$ dengan kontribusi sebesar 14,8\%; (2) ada pengaruh motivasi ekstrinsik $\left(X_{2}\right)$ terhadap prestasi belajar Ekonomi $(Y)$, dengan persamaan garis regresi $Y=58,165+0$, $442 \mathrm{X}_{2}$ dengan kontribusi sebesar 3,8\%; (3) ada pengaruh yang signifikan motivasi intrinsik $\left(X_{1}\right)$, motivasi ekstrinsik $\left(X_{2}\right)$ secara bersama-sama terhadap prestasi belajar ekonomi $(Y)$ dengan persamaan regresi $Y=37,772+0,353 \mathrm{X}_{1}+0,269 \mathrm{X}_{2}$ dengan kontribusi sebesar $16,1 \%$.

Berdasarkan uji hipotesis pertama bahwa ada pengaruh yang signifikan motivasi belajar intrinsik terhadap prestasi belajar ekonomi melalui persamaan garis regresi $\mathrm{Y}=$ $48,690+0,378 X_{1}$ dengan $\mathrm{F}$ hitung $=14.083$ dan $\mathrm{p}<0,05$ maka hasil pengujian tersebut adalah signifikan dan linier sehingga $\mathrm{H}_{0}$ ditolak dan $\mathrm{H}_{1}$ diterima. Berdasarkan hasil analisis regresi parsial ini, motivasi belajar intrinsik bisa dijadikan sebagai prediktor prestasi belajar. Dengan demikain makin baik motivasi belajar intrinsik maka semakin baik pula prestasi belajar ekonomi siswa. Sebaliknya semakin rendah motivasi intrinsik siswa maka akan semakin rendah pula prestasi belajarnya. Melalui hasil pengolahan data penelitian didapatkan gambaran persentase motivasi belajar intrinsik dengan kategori rendah sebanyak 14,5\%, motivasi belajar intrinsik berkategori sedang sebanyak 68,7\%, dan yang berkategori tinggi sebanyak 16,9\% dari keseluruhan subjek penelitian. Data hasil analisis deskriptif menunjukkan bahwa sebagian besar motivasi intrinsik siswa berada dalam kategori sedang yaitu sebanyak 68,7\%. Ini menegaskan bahwa motivasi belajar intrinsik siswa masih harus terus ditingkatkan untuk mencapai prestasi belajar. Sedangkan untuk variabel prestasi belajar dapat digambarkan bahwa 
subjek penelitian yang memiliki prestasi belajar rendah persentasenya 8,4\%, persentase $82 \%$ pada kategori prestasi belajar sedang, dan 9,6\% pada kategori tinggi dari keseluruhan subjek penelitian. Dari data ini diperoleh kesimpulan bahwa sebagian besar prestasi belajar ekonomi siswa berada pada kategori sedang.

Determinasi motivasi belajar intrinsik adalah sebesar 14,8\%. Dengan kata lain, prestasi belajar ekonomi siswa dipengaruhi sebesar 14,8\% oleh motivasi belajar belajar intrinsik. Hal ini sesuai dengan pendapat Clark (dalam Sujana, 2005) bahwa faktor internal khususnya motivasi intrinsik sangat dominan menentukan hasil belajar dibandingkan dengan faktor eksternal. Temuan ini sejalan dengan hasil penelitian Sufianti (2006) yang mengatakan bahwa motivasi intrinsik lebih banyak terdapat pada mahasiswa dibanding motivasi ekstrinsik.

Berdasarkan uji hipotesis kedua yang menyatakan bahwa ada pengaruh motivasi belajar ekstrinsik terhadap prestasi belajar ekonomi siswa SMA Nahdlatul Wathan Pancor melalui persamaan $Y=58,165+0,442 X_{2}$ dengan Nilai $F_{\text {hitung }}=3,192$ dan $p(0,078)$ $>0,05$ maka hasil pengujian tersebut adalah tidak signifikan. Hasil penelitian ini menunjukkan bahwa tidak terdapat hubungan yang positif dan signifikan antara motivasi belajar ekstrinsik $\left(X_{2}\right)$ dengan Prestasi Belajar Ekonomi (Y) yang ditunjukkan dengan koefisien korelasinya 0,195. Hal ini memberikan arti bahwa tingginya prestasi siswa tidak begitu banyak ditentukan oleh motivasi belajar ekstrinsik. Pada penelitian ini prestasi belajar siswa tidak terlalu tergantung pada motivasi ekstrinsik tetapi lebih dominan ditentukan oleh motivasi intrinsik melalui kesadaran para siswa untuk belajar mandiri.

Pengaruh motivasi belajar intrinsik terhadap prestasi belajar lebih kuat dibandingkan dengan motivasi belajar ekstrinsik. Hal ini terbukti ketika diuji terpisah antara variabel bebas dengan variabel terikat. Nilai koefisien korelasi motivasi belajar intrinsik dengan prestasi belajar Ekonomi adalah 0,385 sedangkan nilai koefisien korelasi motivasi belajar ekstrinsik dengan prestasi belajar ekonomi adalah sebesar 0,195 .

Besar sumbangan motivasi belajar ekstrinsik dalam penelitian ini sebesar 3,8\% yang berarti bahwa prestasi belajar ekonomi siswa ditentukan oleh variabel motivasi belajar ekstrinsik sebesar 3,8\%. Hasil temuan penelitian ini sama dengan hasil penelitian yang dilakukan oleh Sufianti (2006) bahwa prestasi belajar mahasiswa sedikit ditentukan oleh motivasi ekstrinsik tetapi lebih banyak ditentukan oleh motivasi intrinsik karena motivasi yang timbul dari dalam diri sendiri karena lebih bertahan lama dan mendasar. Hasil penelitian Sufianti juga membuktikan bahwa motivasi intrinsik lebih dominan dalam menentukan semangat belajar mahasiswa. Hal ini memberikan arti bahwa makin baik motivasi belajar intrinsik seorang siswa dalam melakukan pekerjaan belajarnya maka makin baik pula prestasi belajarnya atau sebaliknya. Keterangan di atas menegaskan bahwa sangat tepat variabel motivasi belajar intrinsik menentukan prestasi belajar siswa. Dengan demikian ada kaitan antara teori yang dijadikan landasan dalam pengajuan hipotesis dengan hasil penelitian yang diperoleh.

Terkait dengan Uji hipotesis ke tiga, hasil penelitian ini menunjukkan bahwa ada pengaruh yang signifikan motivasi belajar intrinsik dan ekstrinsik secara bersama-sama terhadap prestasi belajar ekonomi siswa kelas XI dan XII Tahun Ajaran 2012/2013. Hasil analisis data menunjukkan bahwa motivasi belajar intrinsik $\left(X_{1}\right)$ dan motivasi

DOI: 10.29408/edc.v12i1.1320 
belajar ekstrinsik $\left(X_{2}\right)$ secara simultan berpengaruh secara signifikan terhadap prestasi belajar ekonomi $(\mathrm{Y})$. Hal ini dibuktikan dengan persamaan garis regresi ganda $\mathrm{Y}=$ $37,772+0,352 X_{1}+0,269 X_{2}$ yang menunjukkan arah hubungan yang positif antara motivasi belajar intrinsik dan ekstrinsik secara bersama-sama dengan prestasi belajar siswa dalam mata pelajaran ekonomi. Jika motivasi intrinsik dan ekstrinsik meningkat maka akan diikuti pula oleh meningkatnya prestasi belajar siswa.

Selanjutnya dari hasil perhitungan determinasi, diketahui bahwa sumbangan variabel motivasi intrinsik $\left(\mathrm{X}_{1}\right)$ dan motivasi ekstrinsik $\left(\mathrm{X}_{2}\right)$ terhadap prestasi belajar (Y) ditunjukkan oleh $\left(R^{2}\right)=0,161$ atau $16,1 \%$. Angka ini menunjukkan bahwa variabel motivasi instrinsik (X1) dan motivasi ekstrinsik (X2) yang digunakan dalam persamaan regresi ini mampu memberikan pengaruh terhadap variabel prestasi belajar ekonomi (Y) sebesar 16,1\%. Ini berarti adanya determinasi secara signifikan antara motivasi belajar intrinsic dan motivasi belajar ekstrinsik terhadap prestasi belajar dengan angka sebesar 0,161. Hal ini berarti motivasi intrinsik dan motivasi ekstrinsik dapat menjelaskan prestasi belajar siswa sebesar 16,1\%.

Berdasarkan paparan di atas tampak bahwa dengan motivasi belajar intrinsik dan motivasi belajar ekstrinsik yang tinggi maka prestasi belajar dapat dioptimalkan. Kekuatan korelasi kedua variabel bebas dengan variabel terikat secara berurutan adalah motivasi belajar intrinsik, kemudian motivasi belajar ekstrinsik, dan prestasi belajar ekonomi. Dengan demikian variabel motivasi belajar intrinsik dan motivasi belajar ekstrinsik dapat dijadikan prediktor prestasi belajar ekonomi siswa. Dengan kata lain, semakin tinggi motivasi belajar intrinsik dan ekstrinsik siswa secara simultan maka akan menyebabkan tingginya prestasi belajarnya. Sebaliknya semakin rendah motivasi belajar intrinsik dan ekstrinsiknya secara simultan maka akan semakin rendah prestasi belajarnya.

\section{KESIMPULAN}

Berdasarkan hasil analisis data dan pembahasan, diperoleh temuan penelitian sebagai berikut: 1) Pengaruh motivasi belajar intrinsik terhadap prestasi belajar konomi signifikan. Hal ini berarti bahwa semakin baik motivasi intrinsik siswa semakin tinggi pula prestasi belajarnya. Sebaliknya apabila motivasi belajar intrinsik siswa rendah maka semakin rendah pula prestasi belajar siswa. 2) Pengaruh motivasi belajar ekstrinsik terhadap prestasi belajar ekonomi siswa tidak signifikan. Hal ini berarti bahwa prestasi belajar siswa dalam bidang ekonomi tidak ditentukan oleh motivasi ekstrinsik. Determinan motivasi belajar ekstrinsik terhadap prestasi belajar ekonomi adalah sebesar 3,8\% yang berarti sumbangan motivasi ekstrinsik secara terpisah terhadap prestasi belajar hanya 3,8\%. 3) Pengaruh motivasi belajar intrinsik dan motivasi belajar ekstrinsik secara bersama-sama terhadap prestasi belajar siswa signifikan. Hal ini berarti bahwa semakin tinggi motivasi belajar intrinsik dan ekstrinsik maka semakin tinggi pula prestasi belajar siswa. 


\section{DAFTAR PUSTAKA}

Busairi, A.O. 2000. Stress inoculation training and self-statements monitoring techniques in the reduction of test anxiety among adolescent underachievers in Ibadan metropolis, Nigeria. Unpublished Ph.D. thesis, University of Ibadan.

Dalyono, M. 2005. Psikologi Pendidikan. Bandung: PT Remaja Rosdakarya.

Iroegbu, O.M. 1992. The impact of family background factors on academic achievement. Journal of Technical Education, 1, 87-92.

Osokoya, M.M. 1998. Some determinant of secondary School students' academic achievement in Chemistry in Oyo State. Unpublished Ph.D Thesis, University of Ibadan, Ibadan, Nigeria.

Sufianti, Ely .2006. Hubungan antara Motivasi dengan Prestasi Akademik Mahasiswa STIA LAN Bandung. Jurnal Ilmu Administrasi Volume 31, Nomor. 4.

Sudjana. (2006). Metode Statistik. Jakarta: Rineka Cipta

Uno, Hamzah. 2011. Teori Motivasi dan Pengukurannya. Jakarta: Bumi Aksara. 